\title{
Le Monologue au théâtre (1950-2000). La parole solitaire, textes réunis par Florence Fix et Frédérique Toudoire-Surlapierre
}

\section{Sara Arena}

\author{
(2) OpenEdition \\ Journals \\ Edizione digitale \\ URL: http://journals.openedition.org/studifrancesi/9039 \\ DOI: 10.4000/studifrancesi.9039 \\ ISSN: 2421-5856

\section{Editore} \\ Rosenberg \& Sellier
}

\section{Edizione cartacea}

Data di pubblicazione: 1 octobre 2008

Paginazione: 491-492

ISSN: 0039-2944

\section{Notizia bibliografica digitale}

Sara Arena, «Le Monologue au théâtre (1950-2000). La parole solitaire, textes réunis par Florence Fix et Frédérique Toudoire-Surlapierre», Studi Francesi [Online], 155 (LII | II) | 2008, online dal 30 novembre 2015, consultato il 13 janvier 2021. URL: http://journals.openedition.org/studifrancesi/9039; DOI: https://doi.org/10.4000/studifrancesi.9039

Questo documento è stato generato automaticamente il 13 janvier 2021.

\section{cc) (†) $\odot$}

Studi Francesi è distribuita con Licenza Creative Commons Attribuzione - Non commerciale - Non opere derivate 4.0 Internazionale. 


\title{
Le Monologue au théâtre (1950-2000). La parole solitaire, textes réunis par Florence Fix et Frédérique Toudoire-Surlapierre
}

\author{
Sara Arena
}

\section{NOTIZIA}

Le Monologue au théâtre (1950-2000). La parole solitaire, textes réunis par Florence FIX et Frédérique TOUDOIRE-SURLAPIERRE, Dijon, Éditions Universitaires de Dijon, 2006 («Écritures»), pp. 213.

1 Che si presenti come una sequenza isolata all'interno del tessuto drammaturgico o che risolva l'interezza del testo, come avviene nelle pièces costituite da un solo monologo, la parola "solitaria" resta una modalità del tutto particolare all'interno della scrittura teatrale. Trasformando l'azione in narrazione, abolendo la tacita convenzione della "quarta parete", che separa palco e spettatori, e imponendo al fruitore un ascolto tanto più categorico in quanto non mitigato da una pluralità di voci, la parola del monologo in teatro appare quasi paradossale e può essere sottoposta dagli autori a molteplici trattamenti, che i diversi contributi di questa miscellanea tentano di delineare, prendendo in esame l'opera di alcuni drammaturghi moderni e contemporanei, in gran parte francofoni.

2 In un contributo ricco di spunti teorici sul monologo come «mise en parole» del flusso di pensieri e accesso privilegiato alla psiche del personaggio (pp. 21-34), Georges ZARAGOZA studia la rivisitazione del monologo nella pièce Chambres di Philippe Minyana, dove appare strumento di "espulsione" violenta della parola, prima ancora che di introspezione. Un'intervista allo stesso MINYANA, incentrata sulla sua visione della «parole solitaire» - che questo autore interpreta in funzione essenzialmente dialogica, 
in dialogo, cioè, con gli attori, col pubblico e con altri testi - apre il volume. In «Un soir tard, d'ici quelque temps»: Beckett à l'écoute (pp. 35-48), Frédérique tOUDOIRE-SURLAPIERRE analizza la presenza del monologo in La Dernière bande di Beckett, dove appare come dispositivo rivelatore, attraverso la trasgressione degli abituali codici comunicativi in scena, della solitudine e della non-reciprocità insiti nell'atto creativo e nella rappresentazione teatrale, ma anche come spunto di riflessione sui limiti del linguaggio, dell'espressione verbale e dell'ascolto. Le categorie della soggettività $e$ dell'alterità, con particolare riferimento alla luce della voce interiore (per molti versi, "altra") che riecheggia in ogni individuo, ricorrono negli studi di apertura di questo volume: «La parole solitaire», infatti, «fait jouer les modalités du "soi-même comme un autre"» (p. 45).

Nella seconda parte della miscellanea, incentrata sulla «communication impossible», Blandine ÉHNANO indaga finemente la natura e le implicazioni delle «répliques monologuées» su cui è costruito l'incontro dei due personaggi in L'Homme du hasard di Yasmina Reza (Parole solitaire et dialogue amoureux, pp. 69-82). Nel suo contributo ("Je te quitte, Willy, parce que je t'abandonne»: une parole en rupture de communication, pp. 83-93), Isabelle SMADJA si interroga sulla messinscena, nel teatro di Kroetz, dell'«échec» comunicativo, attraverso artifici come la ripetizione, la tautologia e la ricorrenza di frasi sentenziose. Nei rispettivi interventi, Herveline GUERVILLY (Le monologue pour l'autre: sur "4.48 Psychose" de Sarah Kane, pp. 95-103) e André PETITJEAN (Monologue adressé et dialogie. L'exemple de "La nuit juste avant les forêts" de B.-M. Koltès, pp. 105-119) studiano due pièces di Sarah Kane e Bernard-Marie Koltès alla luce delle particolari configurazioni che assume in esse lo schema enunciativo.

4 La terza sezione del libro, "Seul en scène», contiene infine uno studio comparato di Anne MONFORT (Monologues chiffrés et acteur monologal dans les années 1990-2000, pp. 123-136) e un'analisi di Isabelle BARBERIS condotta sulla pièce dell'autore argentino (ma di espressione prevalentemente francese) Copi Loretta Strong (pp. 137-150). Sébastien RUFFO accosta l'opera del canadese Favreau a quella di Dario Fo (Éthos de l'être ensemble. À partir de monologues de Marc Favreau et de Dario Fo, pp. 151-163) e Lydie PARISSE affronta il tema della parola solitaria in teatro mettendolo in relazione con il tema della dissociazione e dell'assenza (De Beckett, Tardieu, Novarina au théâtre contemporain: la parole solitaire, entre incarnation et désincarnation, pp. 191-205). 